\title{
CONSTRAINTS IN THE PHARMACEUTICAL SUPPLY CHAIN TO CLINICS IN THE MAFIKENG AREA, SOUTH AFRICA
}

\author{
SARAH M. MOKGATLHA ${ }^{1} \&$ FRAZER K. KADAMA ${ }^{2}$ \\ ${ }^{1}$ Mmabatho Medical Stores, Department of Health North-West province, South Africa \\ ${ }^{2}$ North-West University, South Africa
}

\begin{abstract}
This paper reports on a study that was founded on Eliyahu Goldratt's 1979 theory of constraints. The theory is based on the premise that real systems have at least one constraint that affects their performance. The study set out to establish the constraints within the pharmaceutical supply chain to clinics attached to Mafikeng Provincial Hospital (MPH) and to seek ways of minimising them. It investigated the factors that led to pharmaceutical outages in clinics. A descriptive research design was adopted for this purpose. Interviews involving respondents from Mmabatho Medical Stores, MPH, clinics attached to MPH and transporters were conducted to gather data. The findings of the study are displayed in narrative and tables. They reveal that there were constraints experienced at each and every one of the links in the pharmaceutical supply chain. The study concluded that the identified constraints were internal in nature and thus could be minimised to improve on the pharmaceutical supply chain. Measures for improvement in the management of the pharmaceutical supply chain were suggested.

Keywords: clinics, delivery, distribution, medical supplies, outsourcing pharmaceuticals, stock, supply chain management, transporters.
\end{abstract}

\section{INTRODUCTION}

The distribution of products from manufacturers to ultimate users often involves a multi-faceted web of reciprocal activities that have to be coordinated to avoid disruptions in the flow of information, funds and products. Participants and activities in such a web constitute a supply chain. A supply chain is a set of individuals and organisations, who through upstream (supply) and downstream (distribution) activities, facilitate flows of raw materials, products, services, finance and information from source to consumer and vice versa (Mentzer et al. [1]). Supply chain management (SCM) is the oversight of materials, information and finances as they move in sequential order from manufacturer to supplier to wholesaler to retailer and ultimately to consumer. The manner in which these elements interact and amplify each other forms the basis for success of a supply chain. Supply chain management is a system-based approach of coordinating intrafirm and interfirm activities within a supply chain for the purpose of improving long-term performance of individual companies and the supply chain as a whole (Mentzer et al. [1]). SCM as philosophy adopts a systems approach and regards the supply chain as an entity where each member directly or indirectly affects the performance of others and the overall supply chain performance (Cooper and Ellram [2]). According to Mentzer et al. [1], SCM has the following characteristics:

- It views the supply chain as a unit that manages the entire flow of inventory from supplier to consumer.

- It coordinates intra and interfirm operations.

- It promotes the creation of customer value and customer satisfaction.

In an effort to improve on SCM, public and private sector organisations are increasingly resorting to outsourcing of non-core activities as opposed to insourcing (McIvor [3]). In 
South Africa, trade unionists and other stakeholders are opposed to the adoption of outsourcing in either sector.

Mmabatho Medical Stores (MMS), a unit in the North-West Department of Health, serves 26 provincial hospitals in the North West (NW) province. Its purpose is to provide pharmaceutical and surgical products to support service delivery; while its functions include: ordering, storage and distribution of pharmaceutical and surgical products to attached provincial hospitals (NWDoH [4]). Efficiency in SCM at MMS is of vital importance given that the availability of pharmaceutical supplies at healthcare facilities is critical to the success of priority health programmes such as anti-retroviral roll-out, tuberculosis control and immunization (NWDoH [4]).

The researchers note that with the exception of distribution which is outsourced to private operators, all operations at MMS are insourced. Supplies from MMS are despatched to provincial hospitals from where they are distributed to attached clinics. Further, they established that Mafikeng Provincial Hospital (MPH) supplies pharmaceuticals to 36 clinics on a bi-weekly basis. Transporters, in the small micro and medium (SMME) sector, are outsourced to distribute supplies from MMS to MPH and from MPH to clinics. There are eight main parties involved in the MPH pharmaceutical supply chain, namely: pharmaceutical manufacturers, suppliers, national and provincial Departments of Health, MMS, MPH, clinics and transporters.

According to NWDoH [4], there were challenges experienced in the pharmaceutical supply chain to clinics in the province. These were attributed, inter alia, to the following factors: hospital pharmacies had limited storage space to accommodate the necessary volumes of clinic stock; clinics lacked adequate storage capacity; and many clinics were located far from their supplier pharmacies.

Culminating from the identified challenges, it was noted that in spite of the realisation by NWDoH [4] that there are regular outages of pharmaceutical supplies in clinics, no studies had been conducted to investigate and address the factors that lead to outages in clinics in the province. There was therefore a need to conduct a study that would assess the pharmaceutical supply chain to the clinics attached to MPH with the aim of identifying constraints there in and to recommend necessary interventions.

Two research questions were considered in the study. The primary research question was: what are the factors that lead to shortages of pharmaceutical supplies at clinics attached to MPH? The secondary research question was: what needs to be done to minimise the shortages of pharmaceutical supplies in clinics? In order to address the research questions, the following objectives were adopted:

- Establish the factors that lead to stock outs of medical supplies in the clinics attached to MPH.

- Recommend measures to minimise stock outages in the clinics.

\section{LITERATURE REVIEW}

\subsection{Primary healthcare}

Primary healthcare (PHC) is the first level of contact for individuals, families and communities within the national healthcare system. It brings healthcare as close as possible to where people live and work. It constitutes the first element of a continuing healthcare process (Naude and Setswe [5]; WHO [6]). Proper management of PHC is vital in increasing population access to healthcare and reducing the burden of disease [6]. 
In South Africa state clinics serve as the PHC facilities for the public. According to NWDoH [4], PHC should be based on the following principles:

- Equity - all citizens must have the same access to services offered.

- Accessibility - people must be able to reach the services with ease.

- Affordability - the service offered must be affordable to everybody.

- Sustainability - the service must be offered on a long-term basis.

According to Mbindyo et al. [7], challenges experienced in the provision of PHC include: shortage of pharmaceutical personnel; poor estimates of consumption; deficient medical supplies storage infrastructure; critical stock outs extending beyond 30 days; and regular interruptions in public sector supply chains. Lack of medicines in the public sector forces patients to purchase medicines from the private sector or forgo treatment if they cannot afford the price; which may result in avoidable deaths (Mokgatlha [8]).

\subsection{Factors leading to shortages of pharmaceutical supplies}

From studies conducted by Kotwani et al. [9], Mendis et al. [10] and Management Science for Health [11], it was deduced that there are four main functions in the medicine supply management cycle, namely selection of medicines, procurement, distribution and use. These functions are guided by policy, law and regulations (Management Science for Health [11]). In spite of elaborate regulations and guidelines being in place, the studies identified the following as contributory factors to pharmaceutical outages in primary healthcare facilities: manufacturing and quality problems; wrong quantification from national through to facility level; poor tracking of stock levels; poor ordering system; poor delivery services; poor consumption statistics; supplying medicines that are not listed on essential drugs list used by clinics; and late or non-payment of suppliers and distributors.

\section{RESEARCH METHOD}

A descriptive research design was adopted. The study was delimited to: clinics attached to MPH in Mafikeng and Ratlou local municipalities in Ngaka Modiri Molema District (NMMD); purposively selected NWDoH officials; and transporters for MMS and MPH. The study restricted itself to matters related to procurement and delivery of medical supplies to clinics. The population comprised four categories, as shown in Table 1.

With the exception of the category of clinics, all units in the other population categories participated in the study. Clinics were selected to participate in the study through stratified sampling. The strata were based on the distance between MPH and its clinics. The numbers of clinics selected from each strata are shown in Table 2.

Table 1: Categories of the study population.

\begin{tabular}{|l|l|}
\hline Population category & Population number \\
\hline Mmabatho Medical Stores & 1 \\
\hline Mafikeng Provincial Hospital & 1 \\
\hline Clinics attached to MPH & 36 \\
\hline Transporters distributing medical supplies for MMS and MPH & 3 \\
\hline
\end{tabular}


Table 2: Clinics attached to MPH in the different strata.

\begin{tabular}{|l|l|l|l|}
\hline Stratum & Radius from MPH & Number of clinics & Sample \\
\hline I & $\leq 10 \mathrm{~km}$ from MPH & 13 & 5 \\
\hline II & Between $11 \mathrm{~km}$ and $20 \mathrm{~km}$ & 8 & 2 \\
\hline III & $>20 \mathrm{~km}$ from MPH & 15 & 5 \\
\hline
\end{tabular}

The official in-charge of stock management at each of the selected clinics was interviewed. The interviewees were purposively selected because of their direct involvement in stock management. Data were collected through face to face interviews, telephonic interviews and non-participatory observation. A Likert scale was applied to operationalise the responses to percentages.

\section{FINDINGS}

Results of the study are presented in charts, tables and narrative.

\subsection{Educational level of respondents}

All respondents in the study were asked to indicate their highest level of education. The responses of participants in clinics are captured in Table 3.

Results indicate that only $32 \%$ of the respondents in clinics were trained in clinical stock management, while the majority $(58 \%)$ were trained as healthcare givers.

It was revealed that respondents at $50 \%$ of the clinics had received training in workshops on procurement of pharmaceutical supplies. Both the MMS warehouse manager and the MPH pharmacy manager had relevant university degrees and 10 years of working experience.

\subsection{Causes of stock outages}

Participants, in clinics, MPH and MMS were asked to give their views on the causes of stock outs in their units. Their responses are captured in Tables 4, 5 and 6 respectively.

\subsubsection{Causes of outages in clinics}

Respondents in clinics were interviewed on the possible causes of stock outages in clinics. Their views are captured in Table 4.

The results indicate that the respondents in clinics exonerated themselves from the outages of pharmaceutical in clinics and squarely placed the blame on MPH. However, they were non-committal with regard to the role of MMS; this could be due to the fact that they do not have direct interactions with MMS.

Table 3: Highest level of education attained.

\begin{tabular}{|l|l|l|l|l|}
\hline \multirow{5}{*}{} & \multicolumn{4}{|c|}{ Level of education } \\
\cline { 2 - 5 } & Pre-college & $\begin{array}{l}\text { Pharmacy } \\
\text { assistant }\end{array}$ & $\begin{array}{l}\text { Diploma } \\
\text { Nursing }\end{array}$ & BSc Nursing \\
\cline { 2 - 5 } Number & 1 & 4 & 6 & 1 \\
\hline
\end{tabular}


Table 4: Causes of stock outs in clinics.

\begin{tabular}{|l|l|l|l|c|c|}
\hline Cause & $\begin{array}{l}\text { Strongly } \\
\text { agree } \\
(\%)\end{array}$ & $\begin{array}{l}\text { Agree } \\
(\%)\end{array}$ & $\begin{array}{l}\text { Neutral } \\
(\%)\end{array}$ & $\begin{array}{l}\text { Disagree } \\
(\%)\end{array}$ & $\begin{array}{l}\text { Strongly } \\
\text { disagree } \\
(\%)\end{array}$ \\
\hline Failure to place orders on time & 0 & 27 & 9 & 64 & 0 \\
\hline Lack of stock at MPH & 46 & 46 & 8 & 0 & 0 \\
\hline Lack of stock at MMS & 18 & 18 & 64 & 0 & 0 \\
\hline Lack of transport & 18 & 0 & 18 & 36 & 28 \\
\hline $\begin{array}{l}\text { Other contributing factors specified: } \\
\text { Increased number of patients during school holidays and festive seasons affects stock levels; orders are } \\
\text { lost at MPH; and shortfalls in supplies. }\end{array}$
\end{tabular}

\subsubsection{Causes of stock outages at MPH}

Respondents at MPH were interviewed on the possible causes of stock outages in clinics. Their views are captured in Table 5.

The official exonerated the hospital pharmacy staff of being instrumental in the drug outages experienced at MPH; however, she attributed the blame to an unreliable drug supply management system, MMS and transporters.

\subsubsection{Causes of outages at MMS}

The respondent at MMS cited a number of factors which contributed to stock outages at MMS. These are captured in Table 6.

Table 5: Causes of stock outages at MPH.

\begin{tabular}{|l|l|l|l|l|l|}
\hline Causes & $\begin{array}{l}\text { Strongly } \\
\text { agree } \\
(\%)\end{array}$ & $\begin{array}{l}\text { Agree } \\
(\%)\end{array}$ & $\begin{array}{l}\text { Neutral } \\
(\%)\end{array}$ & $\begin{array}{l}\text { Disagree } \\
(\%)\end{array}$ & $\begin{array}{l}\text { Strongly } \\
\text { disagree } \\
(\%)\end{array}$ \\
\hline Failure to place orders on time & 100 & & & & 100 \\
\hline Lack of stock at MMS & 100 & & & \\
\hline $\begin{array}{l}\text { Lack of transport to deliver stock from MMS } \\
\text { to hospital pharmacy }\end{array}$ & & & \\
\hline $\begin{array}{l}\text { Other contributing factors specified: } \\
\text { In house system malfunction and non-adherence to the delivery schedule. }\end{array}$ \\
\hline
\end{tabular}

Table 6: Causes of stock outages at MMS.

\begin{tabular}{|l|l|l|l|l|l|}
\hline Cause & $\begin{array}{l}\text { Strongly } \\
\text { agree } \\
(\%)\end{array}$ & $\begin{array}{l}\text { Agree } \\
(\%)\end{array}$ & $\begin{array}{l}\text { Neutral } \\
(\%)\end{array}$ & $\begin{array}{l}\text { Disagree } \\
(\%)\end{array}$ & $\begin{array}{l}\text { Strongly } \\
\text { disagree } \\
(\%)\end{array}$ \\
\hline Delay by MMS in placing orders to suppliers & 100 & & & & \\
\hline Failure to place orders on time by MPH. & 100 & & & & \\
\hline Lack of stock at pharmaceutical companies & 100 & & & & \\
\hline $\begin{array}{l}\text { Failure by pharmaceutical companies to supply } \\
\text { full quantities ordered by the MMS }\end{array}$ & 100 & & & & \\
\hline Disruptions in supplies due to late payments & 100 & & & \\
\hline $\begin{array}{l}\text { Other contributing factors specified: } \\
\text { Lack of pharmaceutical raw material in factories; non-adherence to delivery lead times; late or non- } \\
\text { payment of supplier accounts; and due to short notice, suppliers that are awarded tenders do not have } \\
\text { sufficient time stock pile before commencement of contracts. }\end{array}$ \\
\hline
\end{tabular}


The results portray an intricate system that experiences problems due to a number of factors that include an unreliable management information system; an uncoordinated tendering process; and failure to comply with contractual obligations by various parties.

\subsubsection{Storage facilities in clinics}

Respondents at clinics were asked about the suitability of storage facilities in their clinics. The majority (92\%) indicated their storage facilities did not comply with best practice. Through observation, the researchers noted that there was insufficient storage space at $75 \%$ of the clinics; and insufficient shelves at $8 \%$ of the clinics.

\subsubsection{Stock levels at MMS and MPH}

The respondents at MMS and MPH were asked the following questions?

- Do you have items that are over stocked?

- Do you have items that are under stocked?

- Are there items that are currently out of stock?

They both answered in the affirmative to all questions.

\subsubsection{Stock level management}

Officials responsible for ordering supplies at the clinics, MPH and MMS were asked to indicate the measures put in place to monitor levels of medical supplies that are used in their facilities. Responses indicate that all clinics processed orders manually using stock cards; each item batch in store had its stock card; and each stock card showed the re-order levels for each item. Whereas there was no drug supply management system (DSMS) for stock management in clinics, there was a good system in place to manually process orders.

There were DSMS at MMS and MPH. Staff had received training on the use of the DSMS however, serious problems were experienced in stock level management at the two institutions.

\subsubsection{Interventions to minimise stock outs}

Participants were asked to indicate measures undertaken in the event of stock outs. Responses from clinics indicate that the majority of respondents did not devise any interventions but would wait for the next routine delivery. While at MPH, they request doctors to prescribe alternative medicines or collect stock from MMS. And at MMS, they make regular follow ups with the suppliers to deliver stock.

The researchers enquired whether situations ever occur where officials are required to place emergency orders. Both MMS and MPH answered in the negative while the majority in clinics answered in the affirmative.

\subsubsection{Delivery of medical supplies to clinics and MPH}

Officials at clinics were asked to indicate their opinions regarding outsourced transport services rendered by SMME. By consensus, they agreed that transporters were doing a sterling job however, they were faulted for late deliveries and poor working relationships.

\subsubsection{Operational challenges experienced by transporters}

Enquiries were made about challenges that transporters encountered in their business operations. The following challenges were identified: short contract periods as such transporters could not acquire loans to buy reliable vehicles; the tendering process was highly competitive making it difficult for transporters to break-even and make profit; poor returns on investment and uncertainty of winning more tenders deter transporters from investing in 
appropriate vehicles; high distribution costs in the industry; poor road conditions; and late and inconsistent payments from government result in cash flow problems. Furthermore, factors such as: lack of people skills among health officials; staff not promptly processing receipt of supplies thus causing delays; and sometimes transporters arrive at clinics only to find that there is no one to receive supplies serve to exacerbate the woes of the transporters.

\section{DISCUSSION}

This section discusses factors pertinent to pharmaceutical outages in clinics in the Mafikeng area. A number of contributory factors were identified in the entire supply chain; many were interrelated while others cut across the entire chain. This paper emphasises the following factors: tender allocations; unreliable statistics; a flawed ordering process; inadequate storage facilities; and disgruntled transporters.

Tenders are processed at both national and provincial levels, successful bidders are notified and they in turn place orders with manufacturers. The study established that delays experienced in the tender awarding process do not accord successful bidders ample time to liaise with manufacturers to acquire sufficient stock levels before their contracts come into effect. This leads to outages at MMS and subsequently in the entire chain.

Further, the study established that there were delays in processing payments to service providers by both national and provincial Departments of Health. This often forced service providers to withhold services thus leading to outages in the supply chain.

The study established that outages may also result from planning statistics that do not take seasonal and annual population fluctuations into account. This notion is backed by the finding that the majority of clinics indicated that they regularly experienced outages especially during Christmas and Easter holidays due to the influx of students on vacation and migrant workers.

All orders placed to the manufacturers are informed by statistics compiled at various levels of the supply chain. False statistics will result in either overstocking or understocking. Overstocking may result in financial loss when drugs expire while still in stores; on the other hand, understocking results in outages in the entire chain.

The study established that there are five ordering points in the supply chain, however, the investigations were limited to four points: suppliers, MMS, MPH and clinics. With the exception of clinics where orders were manually processed, all orders were placed online using a drug supply management system (DSMS). The manual ordering process was found to be quite elaborate and time consuming and as such resulted delays in finalisation of orders at the clinics. Further, orders were frequently lost while in transit from clinics to MPH.

At the time of the study, the DSMS had been in use for three years; however, the operators were not proficient with the system despite the fact that they had been trained on its operations. Clearly, the DSMS is not user friendly, orders are not promptly processed which leads to stock outages in the supply chain.

An analysis of the qualification of human capital involved with the supply chain in clinics shows that the majority were nurses whose main area of focus is patient care and not stock management. The nurses were required to divide their attention between patient care and stock management which compromised their performance on both fronts.

Due to lack of adequate storage facilities, the majority of clinics could not order sufficient quantities of stock; as such, they constantly experienced stock outs before the next scheduled deliveries.

A number of problems encountered by transporters resulted in outages in the supply chain, they include: regular breakdown of vehicles due to old age; short term contracts which made it difficult for them to obtain loans from banks to replace vehicles; and poor road conditions. 


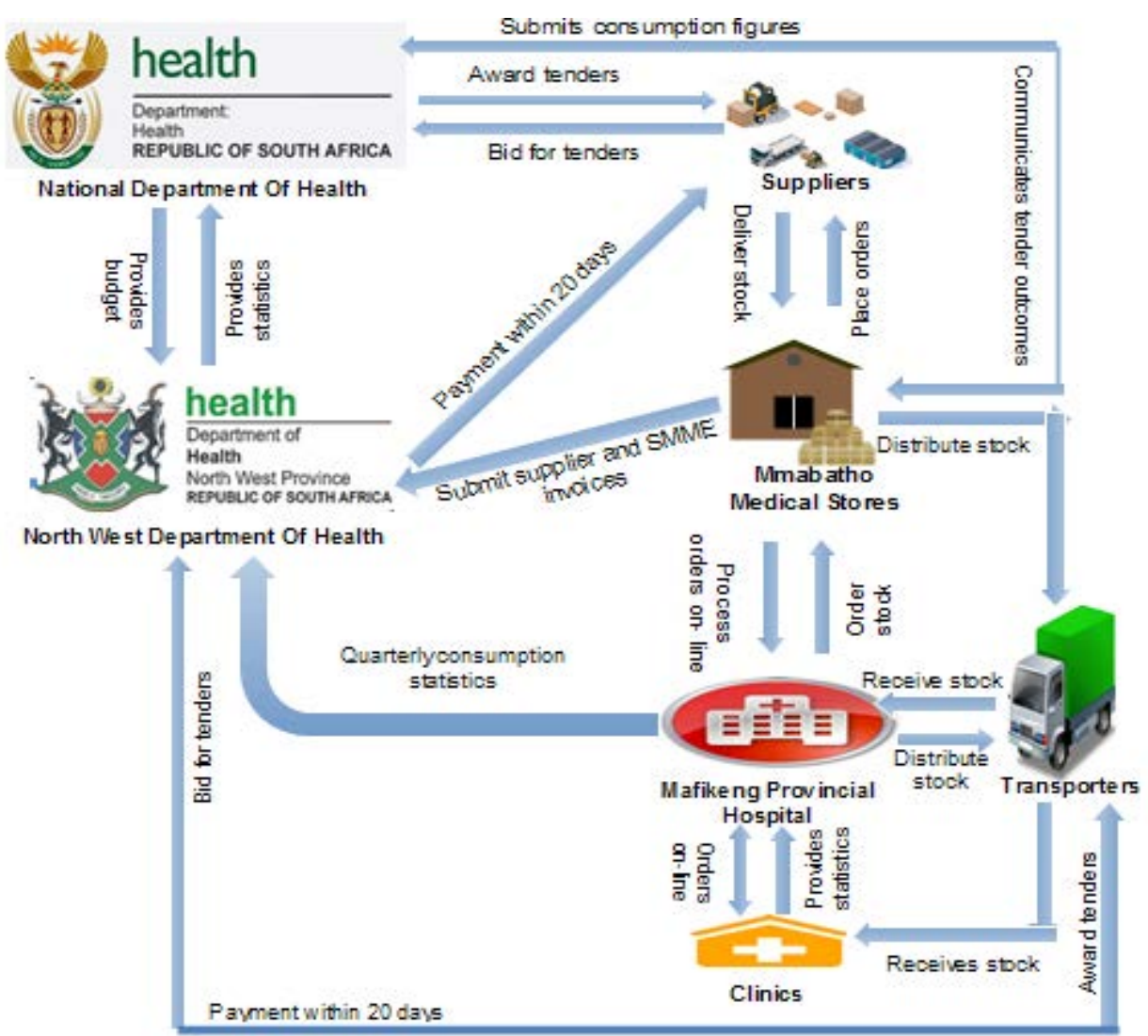

Figure 1: The organizational framework for the pharmaceutical supply chain.

\section{CONCLUSION AND RECOMMENDATIONS}

On analysis of the contributory factors identified, one realises that they all belong within the micro-environment of the supply chain; they are thus within the control of the key players in the supply chain. As such, the untenable status quo can be salvaged through appropriate interventions. It is therefore the recommendation of this study that the following measures should be implemented by the concerned parties:

- Timelines should be factored in the tender awarding process to ensure that successful bidders have sufficient time to adequately stock pile before the commencement dates of their contracts.

- The turnaround time for processing service providers and suppliers' payments should not exceed 20 working days.

- Department of Health should engage the services of biostatisticians to compile statistics that factor in seasonal and annual population fluctuations. In this way, reliable pharmaceutical consumption levels can be computed and applied to ensure appropriate stocking in the entire supply chain.

- The department should consider replacing the DSMS currently in use with a more user friendly centrally managed system.

- Stock management in clinics should be handled by Pharmacy Assistants. 
- Introduce barcode scanning technology in stores and clinics to improve on stock level tracking and to minimise time wastage caused by manual processing of orders in clinics.

- Storage facilities at all clinics should be upgraded to accommodate stock requirements based on statistical forecasts and also to comply with the Medicines Control Council requirements. The department should tentatively provide prefabricated buildings or park homes to increase storage capacity at clinics as they await permanent.

- Transporters should be given long term contracts (at least seven years) to enable them to acquire reliable trucks to minimise outages due to mechanical breakdowns.

- The intricate flow of activities in the supply chain should be coordinated as illustrated in Fig. 1.

\section{REFERENCES}

[1] Mentzer, J.T., DeWitt, W., Keebler, J.S., Min, S., Nix, N.W., Smith, C.D. \& Zacharia, Z.G., Defining supply chain management. Journal of Business Logistics, 22(2), pp. 1-25, 2001.

[2] Cooper M.C. \& Ellram L.M., Characteristics of supply chain management and the implications for purchasing and logistics strategy. The International Journal of Logistics Management, 4(2), pp. 13-24, 1993.

[3] McIvor, R., The Outsourcing Process - Strategies for Evaluation and Management, Cambridge University: New York, 7 pp., 2005.

[4] North West Department of Health (NWDoH), Budget speech, Government Printer: Mafikeng, 2011.

[5] Naude, M. \& Setswe, G., Basic Community Health Nursing, Heinemann Publishers: Cape Town, 2000 pp.

[6] World Health Organization (WHO), Regional Office for the Western Pacific, Primary health care review project. Region specific report, Manila, Philippines, 2002.

[7] Mbindyo, R., Siyoi, F., Mucheru, N., Cepuch, C. \& Wakori, J., Measuring access to essential medical supplies in Kenya using the standardised WHO household survey, 2008.

[8] Mokgatlha, M.S., Effectiveness of the pharmaceutical supply chain to clinics attached to Mafikeng Provincial Hospital, Mini-dissertation, NWU, Mafikeng, 2013.

[9] Kotwani, A. et al., Prices and availability of common medical supplies at six sites in India using standard methodology. Indian J Med Res 125(5), pp. 645-654, 2007.

[10] Mendis, S. et al., The availability and affordability of essential medical supplies for chronic diseases in six low and middle-income countries. Bulletin of the World Health Organization, 85(4), 2007.

[11] Management Science for Health, MDS-3, Managing Access to Medical Supplies and Health Technologies, Management Sciences for Health: Arlington, VA, 2012. 